\title{
Anterior Communicating Artery Aneurysm Uncommon Hemorrhagic Presentation: Case Report
}

\section{Aneurisma de Artéria Comunicante Anterior Apresentação Hemorragia Incomum: Relato de caso}

\author{
Dan Zimelewicz Oberman ${ }^{1}$ Nicollas Nunes Rabelo ${ }^{2}$ Rafael Rego Barros ${ }^{1}$ Othavio Lopes ${ }^{1}$ \\ Jorge Amorim ${ }^{1}$ \\ ${ }^{1}$ Department of Neurosurgery, Hospital Força Aérea do Galeão, Rio de \\ Janeiro, RJ, Brazil \\ 2 Department of Neurosurgery, Santa Casa da Misericórdia de Ribeirão \\ Preto, Ribeirão Preto, SP, Brazil \\ Address for correspondence Dan Zimelewicz Oberman, MD, \\ Department of Neurosurgery, Hospital Força Aérea do Galeão, Rio de \\ Janeiro, Rio de Janeiro, RJ 21941-353, Brazil \\ (e-mail: danzoberman@gmail.com).
}

Arq Bras Neurocir 2020;39(1):54-57.

\author{
Abstract \\ Keywords \\ - aneurysm rupture \\ - anterior \\ communicating \\ aneurysm \\ - intraventricular \\ hemorrhage \\ - subarachnoid \\ hemorrhage

\section{Resumo} \\ Palavras-chave \\ - aneurisma roto \\ - aneurisma de artéria \\ comunicante anterior \\ - hemorragia \\ intraventricular \\ - hemorragia \\ subaracnóidea
}

Intracranial aneurysm rupture causes subarachnoid hemorrhage in $80 \%$ of the cases, and it may be associated with intracerebral hemorrhage and/or intraventricular hemorrhage (IVH) in $34 \%$ and $17 \%$ of the patients, respectively. However, on rare occasions, aneurysm rupture may be present causing isolate intracerebral hemorrhage or IVH without subarachnoid hemorrhage.

We describe an unusual case of an anterior communicating aneurysm rupture presented with $\mathrm{IVH}$, without subarachnoid hemorrhage.

Although isolated IVH is rare, aneurysm rupture is a possible condition. Patients presenting with head computed tomography revealing IVH without subarachnoid hemorrhage should be promptly investigated with contrasted image exam to identify and treat possible causes, even in the absence of subarachnoid hemorrhage.

A ruptura do aneurisma intracraniano causa hemorragia subaracnóidea em $80 \%$ dos casos, e pode estar associada a hemorragia intracerebral e / ou hemorragia intraventricular em $34 \%$ e $17 \%$ dos pacientes, respectivamente. No entanto, em raras ocasiões, a ruptura do aneurisma pode estar presente, causando hemorragia intracerebral isolada ou hemorragia intraventricular, sem hemorragia subaracnóidea. Descrevemos um caso incomum de ruptura de aneurisma de comunicação anterior apresentado com HIV, sem hemorragia subaracnóidea. Embora a hemorragia intraventricular isolada seja rara, a ruptura do aneurisma é uma condição possível. Pacientes que apresentam tomografia computadorizada revelando hemorragia intraventricular, sem hemorragia subaracnóidea devem ser prontamente investigados com exame de imagem contrastada para identificar e tratar possíveis causas, mesmo na ausência de hemorragia subaracnóidea. received

July 10, 2019

accepted

October 22, 2019
DOI https://doi.org/

10.1055/s-0039-3402488. ISSN 0103-5355.
Copyright (e 2020 by Thieme Revinter

Publicações Ltda, Rio de Janeiro, Brazil
License terms

(c) $(1) \$$ 


\section{Background}

Subarachnoid hemorrhage (SAH) is a life-threatening condition and accounts for 5 to $10 \%$ of all strokes in the United States. ${ }^{1}$ Vascular abnormalities are well documented causes of non-traumatic SAH, with aneurysm rupture being the most common. ${ }^{2,3}$

Subarachnoid hemorrhage from intracranial aneurysm (IA) rupture is a leading cause of stroke disability and death in young patients, with a high mortality rate (50\%) and up to $50 \%$ of morbidity in survivors. ${ }^{4}$

Intracranial aneurysm rupture causes SAH in $80 \%$ of the patients, ${ }^{5}$ and it may be associated to intracerebral hemorrhage (ICH) and/or intraventricular hemorrhage (IVH) in 34\% and $17 \%$ of the patients, respectively. ${ }^{6,7}$

However, on infrequent occasions, aneurysm rupture may be present, causing isolate ICH or IVH without SAH. Thai et $\mathrm{al}^{7}$ reported a rate of only $1.6 \%$ of patients presenting with isolated ICH and/or IVH, leading a poor prognosis.

We describe an unusual case of an anterior communicating aneurysm rupture presenting with IVH, without t SAH.

\section{Case Presentation}

A 70-year-old male with a history of hypertension, type 2 diabetes, dyslipidemia, and previous episode of ischemic stroke presented to the emergency department (ED) of our institution with nausea, fatigue, and mild headache. His medications included Aspirin (Bayer AG, Leverkusen, Germany), atorvastatin, and antihypertensive. The patient denied the use of tobacco, drugs, or family history of a brain aneurysm. After an initial assessment, he presented nausea, vomiting, and drowsiness. On physical examination, his only significant finding was a Glasgow coma scale (GCS) score of 13, without any focal deficits. His blood pressure was $185 \times 100 \mathrm{~mm} \mathrm{Hg}$ and returned to normal $(<140 \times 90 \mathrm{~mm} \mathrm{Hg})$ after treatment with sodium nitroprusside in 7 hours. The remainder of the neurological examination was unremarkable.

A cranial computed tomography (CT) scan was initially performed and revealed a small bleeding in the right occipital horn of the lateral ventricles, early hydrocephalus, and a large ectatic basilar artery measuring $9 \mathrm{~mm}$ in diameter (-Fig. 1). No parenchymal or SAH was present. The patient, therefore, underwent to computed tomography angiography (CTA), showing a saccular aneurysm measuring $\sim 5.8 \times 6.7$ $\times 4.2 \mathrm{~mm}$ in diameter arising from the anterior communicating artery (Acom) (-Fig. 2).

Digital subtraction angiography (DSA) findings confirmed the diagnosis of Acom aneurysm (-Fig. 3). Due to the size, morphology, and location of the aneurysm, we opted for treating it with surgical clipping.

Three days after the diagnosis of a brain aneurysm and before treatment, the patient presented deterioration of the level of consciousness and when the GCS got to 8 , he was intubated. Twenty-four hours later, the patient underwent surgery. The aneurysm was clipped, and an extraventricular drainage was placed. Four days after the surgery, the patient

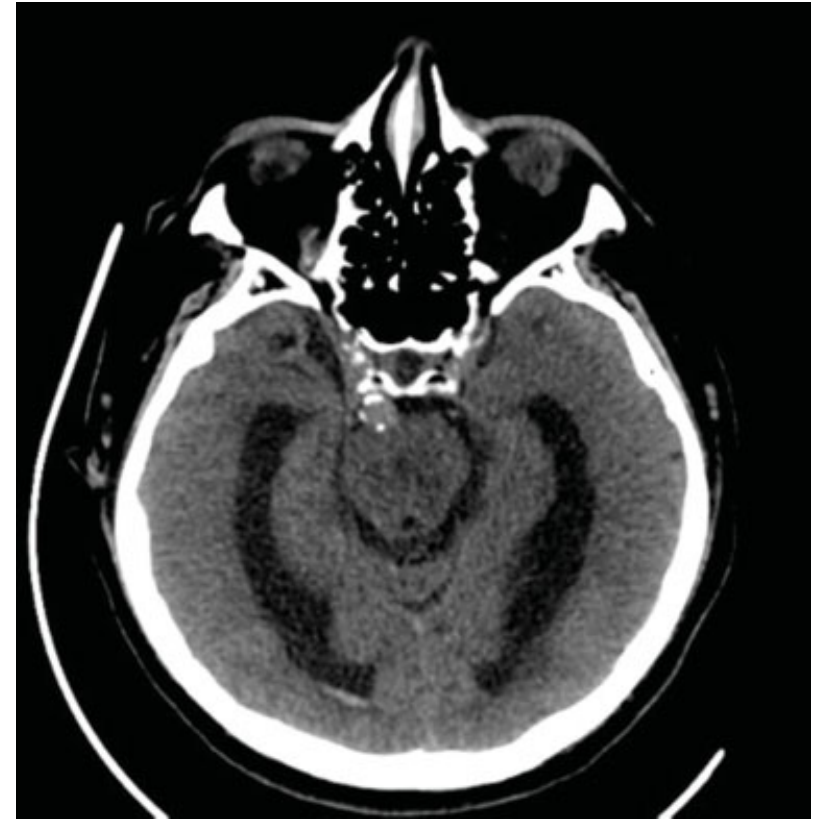

Fig. 1 Computed tomography scan without contrast. Axial plane (A), in which a slightly hyperdense lesion is seen in the occipital horn, without subarachnoid hemorrhage.

developed severe pneumonia, and, despite treatment, the patient died 2 weeks later of septic shock.

\section{Discussion}

Aneurysm rupture is more commonly seen as SAH in noncontrast CT scan, showing blood filling the subarachnoid cisterns. It can also be associated to subdural hematoma, ICH or IVH. Isolated IVH associated to aneurysm rupture is very

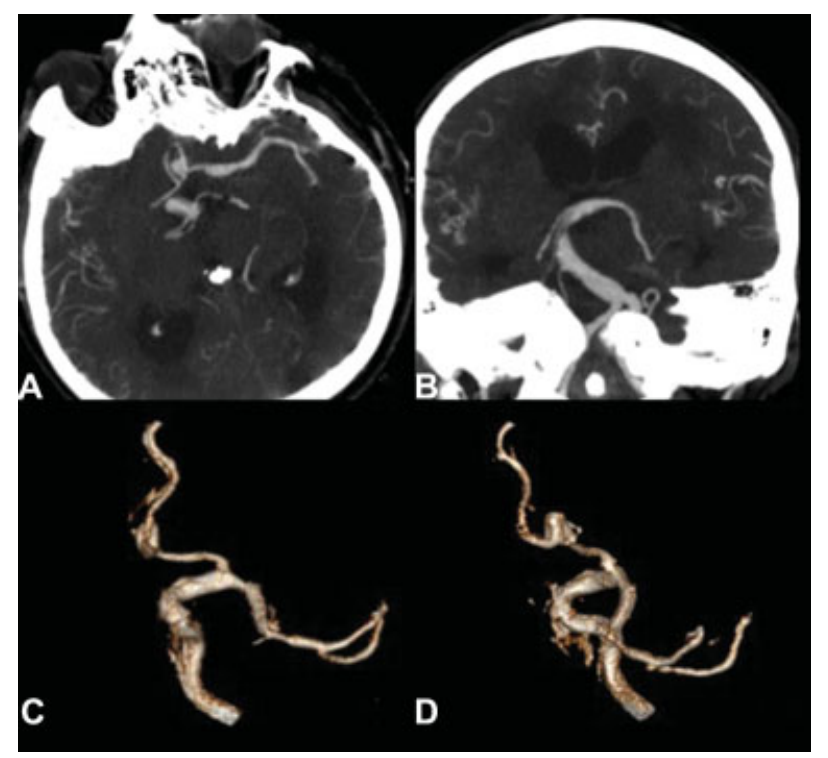

Fig. 2 Intracranial angiotomography. Axial plane (A) shows saccular dilation dependent on the anterior communicating artery with anterior-superior direction. Multiplane reconstruction of maximum intensity showing ectatic basilar trunk (B) and volumetric reconstructions ( $C$ and $D$ ) showing the anterior communicating aneurysm. 


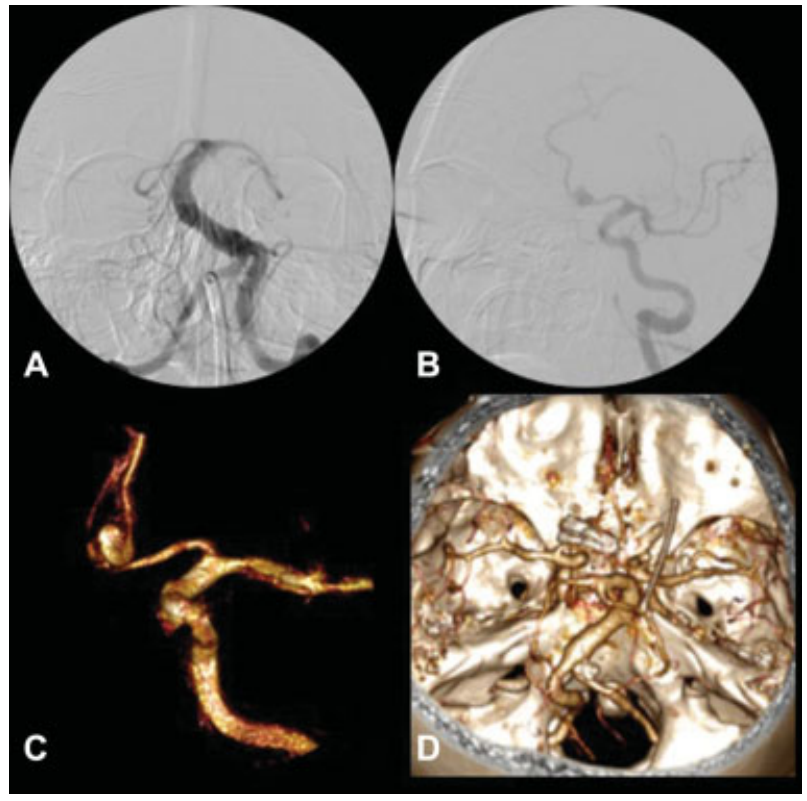

Fig. 3 Digital angiography oblique (A) and coronal (B) prior to surgical treatment. Volumetric reconstruction of digital angiography prior to surgery (C) and volume reconstruction of angiotomography (D) showing aneurysm clipped.

rare, and it is related to high morbidity and mortality, up to $40 \%{ }^{8,9}$ Obstructive or communicating hydrocephalus occurs in $62 \%$ of patients, but only a third require extraventricular drainage. $^{9}$ The development of early hydrocephalus is an independent factor to poor prognosis.

Although many cases of isolated subdural hematoma or ICH associated to aneurysmal bleeding have been reported, ${ }^{10,11}$ only few cases of pure IVH have been cited. ${ }^{7,12,13}$ The two most common causes of isolated IVH are aneurysm rupture and arteriovenous malformation, while moyamoya disease and dural arteriovenous fistula are rarer. $^{8}$

The features and location of the anuerysm can predispose to direct hemorrhage into the parenchyma or ventricular system. Considering the location of the Acom aneurysm in this patient and its anterior superior projection, occipital horn hemorrhage could be explained by direct rupture into the lamina terminalis and then into the ventricular system. ${ }^{14}$

The diagnosis of IVH without SAH is even more challenging depending on the timing when tests are performed. Computed tomography imaging is positive in over $90 \%$ of the cases of SAH on the day the hemorrhage occurs, ${ }^{15}$ and the sensitivity of the test subsequently declines with the passing of time, reaching $50 \%$ by 5 to 7 days after the onset of symptoms. ${ }^{16}$ Delay in performing a CT scan after bleeding might lead to false negative results and increase poor prognosis outcome. Thai et $\mathrm{al}^{7}$ reported 6 patients had a sentinel event on average of 6.3 days before admission for head CT imaging. Due to the small amount of blood and an IVH without SAH in our patient, the diagnosis of aneurysm rupture and its treatment were delayed. This might have contributed to the decreased level of consciousness and poor prognosis of the patient.
Flint et $\mathrm{al}^{8}$ found that catheter angiogram was performed in $52 \%$ of the cases of IVH, with the identification of the bleeding source in 56\%. A causative lesion was identified in $44 \%$ of the patients, who were treated accordingly. The routine catheter angiography in IVH is warranted to identify potentially treatable causes of hemorrhage. This has direct implications in the management of these patients. Therefore, careful radiological examination is necessary to evaluate cases of isolated ventricle hemorrhage.

\section{Conclusions}

This is a case of IVH without SAH caused by rupture of an Acom aneurysm. After extensive neuroimaging investigation, an underlying aneurysm was discovered. Although isolated IVH is rare, aneurysm rupture is a possible condition. Patients presenting with head CT revealing IVH without SAH should be promptly investigated with contrasted image exam to identify and treat possible causes, even in the absence of SAH.

\section{Conflict of Interests}

The authors have no conflict of interests to declare.

\section{Reference}

1 Rincon F. Response to journal club: The epidemiology of admissions of nontraumatic subarachnoid hemorrhage in the United States. Neurosurgery 2014;74(02):230-231

2 Kirkpatrick PJ. Subarachnoid haemorrhage and intracranial aneurysms: what neurologists need to know. J Neurol Neurosurg Psychiatry 2002;73(Suppl 1):i28-i33

3 Barnaure I, Liberato AC, Gonzalez RG, Romero JM. Isolated intraventricular haemorrhage in adults. Br J Radiol 2017;90(1069): 20160779

4 Bederson JB, Awad IA, Wiebers DO, et al. Recommendations for the management of patients with unruptured intracranial aneurysms: A Statement for healthcare professionals from the Stroke Council of the American Heart Association. Stroke 2000;31(11): 2742-2750

5 Lawton MT, Vates GE. Subarachnoid Hemorrhage. N Engl J Med 2017;377(03):257-266. Doi: 10.1056/nejmcp1605827

6 Pasqualin A, Bazzan A, Cavazzani P, Scienza R, Licata C, Da Pian R. Intracranial hematomas following aneurysmal rupture: experience with 309 cases. Surg Neurol 1986;25(01):6-17

7 Thai QA, Raza SM, Pradilla G, Tamargo RJ. Aneurysmal rupture without subarachnoid hemorrhage: case series and literature review. Neurosurgery 2005;57(02):225-229, discussion 225-229

8 Flint AC, Roebken A, Singh V. Primary intraventricular hemorrhage: yield of diagnostic angiography and clinical outcome. Neurocrit Care 2008;8(03):330-336

9 Giray S, Sen O, Sarica FB, et al. Spontaneous primary intraventricular hemorrhage in adults: clinical data, etiology and outcome. Turk Neurosurg 2009;19(04):338-344

10 Gilad R, Fatterpekar GM, Johnson DM, Patel AB. Migrating subdural hematoma without subarachnoid hemorrhage in the case of a patient with a ruptured aneurysm in the intrasellar anterior communicating artery. AJNR Am J Neuroradiol 2007;28(10): 2014-2016

11 Takeuchi S, Takasato Y, Masaoka H, et al. [Case of ruptured middle cerebral artery bifurcation aneurysm presenting as putaminal hemorrhage without subarachnoid hemorrhage]. Brain Nerve 2009;61(10):1171-1175 
12 Prasad KSM, Dambatta SS, Dervin JE. Intraventricular haemorrhage without subarachnoid haemorrhage due to a ruptured aneurysm. BMJ Case Rep 2009;2009:bcr1120081184-bcr1120081184. Doi: 10.1136/bcr.11.2008.1184

13 Ellis JA, D’Amico R, Altschul D, Leung R, Connolly ES, Meyers PM. Medial lenticulostriate artery aneurysm presenting with isolated intraventricular hemorrhage. Surg Neurol Int 2011;2:92

14 Scholtes F, Signorelli F, Bojanowski MW. Rupture of anterior communicating artery aneurysms during computed tomography angiography: description of the pathway for intraseptal and intraventricular hemorrhage. J Neurosurg 2011;115(03): 617-620

15 Broder JS. Comments on "sensitivity of noncontrast cranial computed tomography for the emergency department diagnosis of subarachnoid hemorrhage". Ann Emerg Med 2008;52(06):767-768, author reply 768

16 Cortnum S, Sørensen P, Jørgensen J. Determining the sensitivity of computed tomography scanning in early detection of subarachnoid hemorrhage. Neurosurgery 2010;66(05):900-902, discussion 903 